\title{
Inhibitory effect of tetramethylpyrazine combined with propranolol on murine hemangioma endothelial cells
}

\author{
Wan-Wan Jin, Jian-Ming Wu, Yi Tong, Ji-Cong Jiang, Hehe Quan, Yu Gao* \\ Department of Dermatology, The Second Affiliated Hospital and Yuying Children's Hospital of Wenzhou Medical University, \\ Wenzhou, Zhejiang 325000, China
}

*For correspondence: Email: ezin8s@163.com

\begin{abstract}
Purpose: To study the inhibitory effect of different doses of tetramethylpyrazine (TMP) combined with the beta-blocker, propranolol (Pro) on hemangioma endothelial (EOMA) cells.

Methods: EOMA cells were cultured in vitro with varying doses of TMP and Pro (5, 10, 20 and 40 uM). The effect of treatments on cell proliferation was assessed by MTT assay, while cell apoptosis was assayed by flow cytometry. The expressions of Bcl-2, Bax, p-mTOR), total-mammalian target of rapamycin (t-mTOR, p-p70S6) and total-p70 ribosomal protein S6 (t-p70S6) proteins were determined using Western blot.

Results: MTT data showed that when used alone, TMP had no significant inhibitory effect on EOMA cells $(p>0.05)$. However, when TMP was combined with propranolol, there was significant inhibition of EOMA cells, and that the inhibition is dependent on TMP dose. Flow cytometry results showed that the combination of TMP and Pro induced EOMA cell apoptosis dose-dependently $(p<0.05)$. Moreover, TMP dose-dependently inhibited the phosphorylation of mTOR and p7OS6 in EOMA cells, and enhanced Bax expression, but downregulated Bcl-2 $(p<0.05)$.

Conclusion: These results suggest that TMP enhances the inhibitory influence of Pro $p$-mTOR and $p$ p-70S6 in EOMA cells in a dose-dependent manner. Thus, TMP may enhance Pro-induced inhibition of the growth of endothelial cells, and promote apoptosis through suppression of activation of PI3KJAKT signal route. These findings provide a theoretical basis for the clinical application of TMP/Pro combination for the treatment of hemangioma.
\end{abstract}

Keywords: Hemangioma, Propranolol, Tetramethylpyrazine, Mouse hemangioma endothelial cells, Mammalian target of rapamycin, p70 ribosomal protein S6

\begin{abstract}
This is an Open Access article that uses a fund-ing model which does not charge readers or their institutions for access and distributed under the terms of the Creative Commons Attribution License (http://creativecommons.org/licenses/by/4.0) and the Budapest Open Access Initiative (http://www.budapestopenaccessinitiative.org/read), which permit unrestricted use, distribution, and reproduction in any medium, provided the original work is properly credited.

Tropical Journal of Pharmaceutical Research is indexed by Science Citation Index (SciSearch), Scopus, International Pharmaceutical Abstract, Chemical Abstracts, Embase, Index Copernicus, EBSCO, African Index Medicus, JournalSeek, Journal Citation Reports/Science Edition, Directory of Open Access Journals (DOAJ), African Journal Online, Bioline International, Open-J-Gate and Pharmacy Abstracts
\end{abstract}

\section{INTRODUCTION}

Hemangioma is a congenital benign tumor or vascular malformation that often occurs in the skin and soft tissues of infants and young children. In general, it occurs in the mouth or maxillofacial region, especially in oral mucosa, facial skin and facial subcutaneous tissues [1]. Most cases of hemangioma can resolve on their own, but may give rise to such problems as scars and pigmentation after self-resolving [2]. A small number of hemangioma may affect tissue or organ function due to their specific location or excessive volumes [3]. Thus, the disease may be 
life-threatening, which makes active treatments necessary. Apart from surgery, medication is one of the main means of treating hemangioma. Currently, drugs including $\beta$-blockers, hormones, interferons and cytotoxic agents are used for treating hemangioma. However, these drugs have certain adverse effects which limit their application in clinical practice [4,5]. Consequently, research has focused on the development of safer and more effective drugs for treating hemangioma.

Chuangxiong (Ligusticum chuanxiong Hort.) refers to the dried radix of the umbelliferous plant, with the original name of XiongQiong. It is native to Sichuan and is currently grown in several provinces in China. Modern pharmacological studies have shown that chuanxiong has antioxidant, neuroprotective, anti-inflammatory and antibacterial properties $[6,7]$. There are more than 100 pharmacologically active compounds in chuanxiong. These biologically active components are classified into four categories i.e. phenols and organic acids (e.g. ferulic acid), benzoquinones (e.g. ligustilide), alkaloids (e.g. tetramethylpyrazine), and polysaccharides $[8,9]$.

Tetramethylpyrazine (TMP, Figure 1) is an alkaloid derived from plant and microbial fermented products. The chemical name of TMP is 2, 3, 5, 6-tetramethylpyrazine, and it can be synthesized in the laboratory. Pharmacological studies have shown that TMP exerts antithrombotic effects, and is involved in preventing and treating cerebral ischemia, improving microcirculation, protecting coronary arteries, protecting cardiomyocytes and preventing myocardial ischemia and reperfusion injury [10 12]. As a new angiogenesis inhibitor, it controls the formation of tumor blood vessels [13]. There are limited reports on the effect of TMP on hemangioma endothelial cells in China and elsewhere. Therefore, the effect of combination of TMP and Pro on EOMA cells, and the possible mechanism involved were investigated in this study.<smiles>Cc1nc(C)c(C)nc1C</smiles>

Figure 1: Structure of tetramethylpyrazine

\section{EXPERIMENTAL}

\section{Cell lines, drugs and reagents}

Mouse hemangioma EOMA cells were supplied by American Type Culture Collection (ATCC); tetramethylpyrazine was from China Institute for the Control of Pharmaceutical and Biological Products, while propranolol was product of Sigma. Fetal bovine serum (FBS), penicillin, streptomycin, trypsin and high-dose DMEM medium were purchased from GIBCO BRL, while D-Hanks was purchased from Hylcone. Penicillin-streptomycin and trypsin cell digestive fluid were obtained from Biyuntian Biotechnology Research Institute; Bcl-2, Bax, p-mTOR, TmTOR, P-p70S6, T-p70S6 and $\beta$-actin antibodies were products of Abcam; goat antiIgG (horseradish peroxidase label) was purchased from Proteinech Group, while PVDF membrane and ECL luminescence kits were obtained from Abcam. Other reagents were analytically pure.

This research received approval from the Animal Ethical Committee of Department of Dermatology, The Second Affiliated Hospital and Yuying Children's Hospital of Wenzhou Medical University (approval no. 201713409). It was conducted according to the guidelines of "Principles of Laboratory Animal Care" (NIH publication no. 85-23, revised 1985) [14].

\section{Cell culture}

The EOMA cells were seeded in DMEM/F-12 high glucose medium containing $10 \%$ FBS, and maintained in a $5 \% \mathrm{CO}_{2}$ atmosphere at $37{ }^{\circ} \mathrm{C}$ and saturated humidity. The cells were then conventionally passaged. Cells in logarithmic growth phase were selected for use in the experiments.

\section{MTT assay}

The cells in logarithmic growth phase were collected and made into a single cell suspension of density $2 \times 10^{7}$ cells/L, and were then inoculated into a 96-well cell culture plate at 200 $\mu \mathrm{L}$ per well. A blank control group was set up with culture medium but without cells. The Pro group contained EOMA cells with Pro alone, while the treatment groups comprised TMP culture media (200 $\mu \mathrm{l} /$ well) containing different TMP concentrations $(5,10,20$ and $40 \mu \mathrm{M})$, with or without Pro $(5 \mu \mathrm{M})$. Four replicate wells were set up for each group. After incubating for $24 \mathrm{~h}$, the supernatant was aspirated; D-Hanks was added to each well, and thereafter was aspirated.

Low-sugar DMEM was added (200 $\mu \mathrm{L}$ per well), and was aspirated after culturing for $24 \mathrm{~h}$, followed by drug addition. Each group was cultured for $48 \mathrm{~h}$. Subsequently, MTT $(20 \mu \mathrm{L}, 0.5$ g \%) was put into every well, followed by culturing for $4 \mathrm{~h}$, after which the medium was 
removed and replaced with DMSO $(150 \mu \mathrm{L})$, with shaking, to stop the reaction. The 96-well plate was moved into a plate shaker and shaken horizontally for $10 \mathrm{~min}$ to fully dissolve the formazan crystals formed. The absorbance $(A)$ of each well was measured against blank at a wavelength of $490 \mathrm{~nm}$ (4 parallel wells per group, repeated 3 times independently) [15]. Inhibition $(\mathrm{H})$ of tumor cell proliferation was calculated using Eq 1.

$H(\%)=\left(1-A_{\text {expt }}\right) / A_{\text {control }} \times 100$.

where $A_{\text {expt }}$ and $A_{\text {control }}$ are the absorbance of the experimental and control groups, respectively.

\section{Determination of apoptosis}

The EOMA cells were seeded at a density of $1 \times$ $10^{9} \mathrm{cells} / \mathrm{L}$ in a 6 -well culture plate with medium (1.2 $\mathrm{mL}$ per well). After the cells were attached, the culture medium was discarded and TMP was added. As before, the concentrations of TMP were set at $5,10,20$ and $40 \mu \mathrm{M}$, and were combined with $5 \mu \mathrm{M}$ Pro. Three duplicate wells were set up in each group. After culturing for 48 $\mathrm{h}$, cells in each well were collected, rinsed thrice in ice-cold PBS, and re-suspended in binding buffer (BF, $200 \mu \mathrm{L}$ ), followed by adding $10 \mu \mathrm{L}$ of membrane-protein V-FITC and $5 \mu \mathrm{L}$ of PI. After gentle mixing, the reaction was allowed to proceed for $0.25 \mathrm{~h}$, after which BF $(300 \mu \mathrm{L})$ was introduced. The degree of apoptosis (\%) was measured using flow cytometry.

\section{Western blot}

Cells at the logarithmic growth phase were cultured with TMP for $24 \mathrm{~h}$, washed 3 times with pre-cooled PBS, and treated with $100 \mu \mathrm{L}$ of cell lysate solution (PBS containing $1 \%$ Nonidet P40, $5 \mathrm{~g} / \mathrm{L} \mathrm{Na}$ deoxycholate, $0.1 \mathrm{~g} / 100 \mathrm{~mL}$ sodium dodecyl sulphate, $0.1 \mathrm{~g} / \mathrm{L}$ PMSF and $10 \mathrm{mg} / \mathrm{L}$ aprotinin) at $4^{\circ} \mathrm{C}$ for $60 \mathrm{~min}$. Following lysis, the mixture was subjected to centrifugation at 11000 $\times \mathrm{g}$ at the same temperature for $600 \mathrm{sec}$, followed by protein assay on the clear supernatant using BCA protein assay kit in line with the kit protocol.

After routine SDS-PAGE electrophoresis and transfer to PVDF membrane, the membrane was incubated with antibodies for Bcl-2, Bax, PmTOR, T-mTOR, P-p70S6, T-p70S6 and $\beta$-actin. After washing with blocking solution, horseradish peroxidase-labeled secondary antibody was added and allowed to react at $37^{\circ} \mathrm{C}$ for $1.5 \mathrm{~h}$. Thereafter, the membrane was washed, ECL was added, and the resultant images were captured with gel imaging system. $\beta$-Actin was used as an internal reference to correct the relative expression of the target protein [16].

\section{Statistical analysis}

The statistical software, Graphpad Prism 7.0 was used for data analysis. Numeric data are expressed as mean $\pm S D$, and comparison between groups was performed using one-way analysis of variance. Comparison between multiple means was performed with Tukey's procedure. Values of $p<0.05$ were considered statistically significant.

\section{RESULTS}

\section{Effect of combination of TMP and propranolol on proliferation of EOMA cells}

Results from MTT assay showed that the use of TMP alone at various concentrations had no appreciable suppressive influence on the proliferation of EOMA cells, while propranolol alone had a certain inhibitory effect on the proliferation of EOMA cells, relative to the blank group. When TMP was combined with Pro, the inhibition of Pro on EOMA cells increased significantly with increase in TMP dose (Figure 2, $p<0.05$ ).

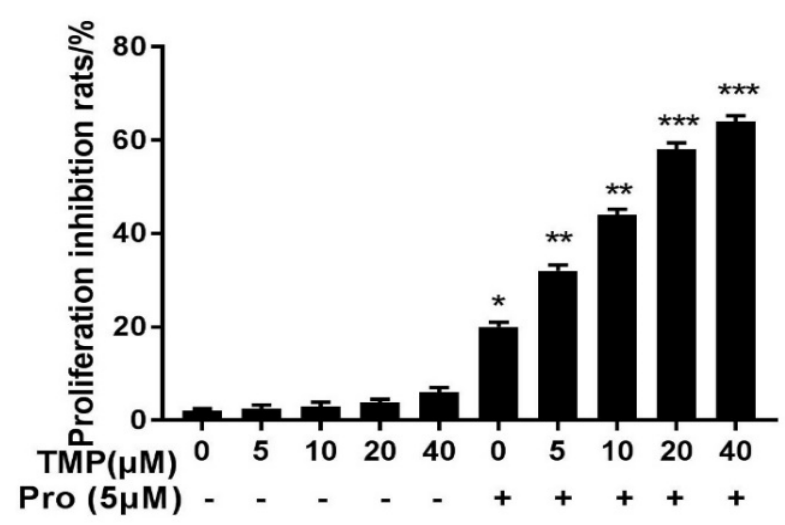

Figure 2: Effect of TMP-Pro combination on EOMA cell proliferation. Data are shown as mean \pm SD from three independent experiments

\section{Effect of combination of TMP and Pro on apoptosis of EOMA cells}

As shown in Figure 3, results from flow cytometry revealed that the combination TMP with Pro significantly and dose-dependently induced EOMA cell apoptosis $(p<0.05$, Figure 3$)$. 
Influence of combination of TMP and Pro on the expressions of Bcl-2, Bax, P-mTOR, TmTOR, P-p70S6 and T-p70S6 proteins in EOMA cells

Western blot assay showed that treatment of hemangioma endothelial cells with combination of TMP and Pro, decreased P-Mtor/T-mTOR and P-p70S6/T-p70S6 ratios. In addition, TMP dosedependently reduced mTOR and p70S6 phosphorylation in EOMA cells (Figures $4 \mathrm{~A}$ and $4 \mathrm{~B})(p<0.05)$. At the same time, the expression of apoptosis-related Bax-2 related was upregulated, while $\mathrm{Bcl}-2$ was significantly downregulated (Figure 4C).
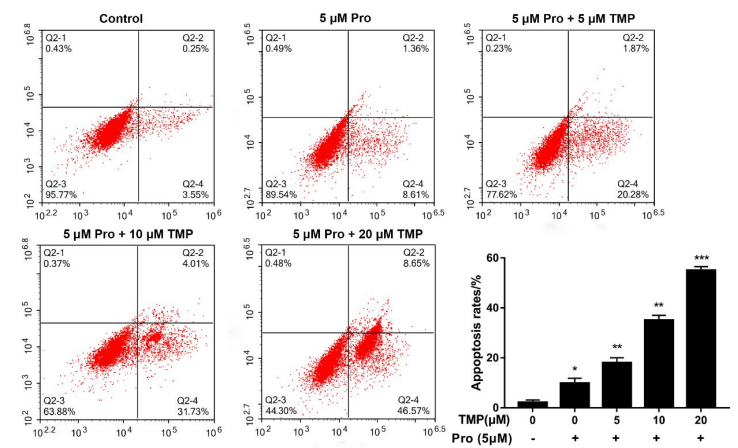

Figure 3: Effect of TMP-Pro combination on apoptosis of EOMA cells. Data represent mean $\pm \mathrm{SD}$; ${ }^{*} p<0.05$, ${ }^{* *} p<0.01,{ }^{* * *} p<0.001$, relative to control

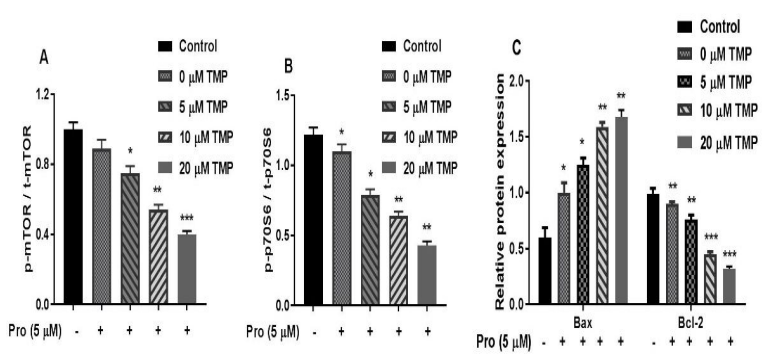

Figure 4: A: Effect of TMP/Pro combination on the expression of p-mTOR; $B$ : Effect of TMP/Pro combination on the expression of p-p70S6; C: Effect of TMP/Pro combination on the expressions of BAX and Bcl-2 ( ${ }^{*} p<0.01 ;{ }^{* *} p<0.05$, compared with control group)

\section{DISCUSSION}

Hemangioma is the most common tumor in infants and young children, with incidence up to 3 - $8 \%$. Some hemangioma can cause serious complications, resulting in body dysfunction, severe damage to physical appearance, or even threat to life of the patient. The cause of hemangioma and the factors affecting its growth are still unclear. Thus, the treatment of hemangioma presents a difficult problem in clinical practice. Although surgical resection and medication offer good therapeutic outcomes, these therapies have some side effects which limit their applications $[4,5]$. Therefore, research efforts on hemangioma have focused on the development of safer and more effective drugs for treating the disease.

Chuanxiong, the dried radix of the umbelliferous plant Ligusticum chuanxiong Hort, is warm in nature and pungent in taste, and enters liver, gallbladder and pericardium meridians, with good and thick smell. It can unblock blood vessels, promote blood circulation and remove blood stasis. Tetramethylpyrazine (TMP) is the main active component of Chuanxiong. It is popularly used in the treatment of kidney, liver, cardiocerebrovascular and respiratory diseases [17]. It is a new angiogenesis inhibitor, and studies have shown that it inhibits the formation of tumor blood vessels [13]. However, there are few reports about the effect of TMP on hemangioma endothelial cells. In this study, the in vitro inhibitory effect of different doses of TMP combined with propranolol on mouse hemangioma endothelial cells (EOMA) was investigated. The findings of this study suggest that TMP enhanced the inhibitory effect of Pro on the growth and apoptosis of mouse hemangioma endothelial cells in a dose-dependent fashion.

Tumor cell growth and metastasis depend on formation of tumor blood vessels, and the process of tumor angiogenesis is complex, involving regulation by multiple genes and signaling pathways. The PI3K/AKT pathway is an important signaling pathway in this process, with AKT as the core protein of the pathway. Activated AKT is involved in the biological processes of tumor cells through direct or indirect mediation in downstream-related proteins and regulation of tumor angiogenesis $[18,19]$. The serine/threonine acid protein kinase, mTOR, is widely involved in several cellular events including autophagy and transcription [20,21]. The p70S6K protein belongs to the family of phosphatidylinositol 3-kinases [22].

It is known that Bax and Bcl-2 belong to the same family; Bax exerts a strong antagonistic effect against Bcl-2, and it can directly promote apoptosis. Studies have shown that Bax and Bcl2 co-regulate cell proliferation and apoptosis [23]. Moreover, mTOR, p70S6, Bcl-2 and Bax are downstream genes related to AKT, and they play important roles in the development of hemangioma $[24,25]$. The PI3K/AKT signaling pathway is abnormally activated in infantile hemangiomas, and its inhibition can significantly promote apoptosis of vascular endothelial cells. 
The results of this study revealed that treating hemangioma endothelial cells with combination of TMP and propranolol upregulated the apoptosis-related Bax, and decreased Bcl-2 expression. The combination treatment also decreased P-Mtor/T-mTOR and P-p70S6/Tp70S6 ratios. Moreover, TMP dose-dependently inhibited mTOR and p70S6 phosphorylation in EOMA cells. These findings suggest that TMP may suppress the growth of hemangioma endothelial cells and promote their apoptosis through suppression of activation of PI3K/AKT signal route.

\section{CONCLUSION}

The findings of this study indicate that the use of varying doses of TMP in combination with the $\beta$ blocker propranolol, significantly inhibits proliferation of mouse EOMA cells. These findings, for the first time, demonstrate that the mechanism involved in the inhibition of the growth of hemangioma cells by TMP/Pro combination may be related to inhibition of the activation of PI3K/AKT signal route. The results of this investigation provide a theoretical background for the treatment of hemangioma using TMP and propranolol.

\section{DECLARATIONS}

\section{Acknowledgement}

This work was supported by Wenzhou Science and Technology Bureau Project (no. Y20180657)

\section{Conflict of interest}

No conflict of interest is associated with this work.

\section{Contribution of authors}

We declare that this work was done by the author(s) named in this article and all liabilities pertaining to claims relating to the content of this article will be borne by the authors. All authors read and approved the manuscript for publication. Wan-Wan Jin and Jian-Ming WU conceived and designed the study. Wan-Wan Jin, Jian-Ming WU, Yi Tong, Ji-Cong Jiang, Hehe Quan and Yu Gao collected and analyzed the data, while Yu Gao wrote the manuscript. WanWan Jin and Jian-Ming WU contributed equally to this work and should be considered as co-first authors.

\section{Open Access}

This is an Open Access article that uses a funding model which does not charge readers or their institutions for access and distributed under the terms of the Creative Commons Attribution License (http://creativecommons.org/licenses/by/ 4.0) and the Budapest Open Access Initiative (http://www.budapestopenaccessinitiative.org/rea d), which permit unrestricted use, distribution, and reproduction in any medium, provided the original work is properly credited.

\section{REFERENCES}

1. Nieuwenhuis $K$, de Laat $P C$, Janmohamed $S R$, Madern $G C$, Oranje AP. Infantile Hemangioma: Treatment with Short Course Systemic Corticosteroid Therapy as an Alternative for Propranolol. Pediatr Dermatol 2013; 30(1): 64-70.

2. Bayliss SJ, Berk DR, Van Hare GF, Balzer D, Yamada K, Lueder G, Lanoel A, de la Fuente V, Cordisco MR. Re: Propranolol Treatment for Hemangioma of Infancy: Risks and Recommendations. Pediatr Dermatol 2010; 26(5): 610-614.

3. Devouassoux-Shisheboran M, Hayashi T, Linnoila RI, Koss MN, Travis WD. A clinicopathologic study of 100 cases of pulmonary sclerosing hemangioma with immunohistochemical studies: TTF-1 is expressed in both round and surface cells, suggesting an origin from primitive respiratory epithelium. Am J Surg Pathol 2000; 24(7): 906-916.

4. Ayturk UM, Couto JA, Hann S, Mulliken JB, Williams $K L$, Huang AY, Fishman SJ, Boyd TK, Kozakewich HPW, Bischoff $\mathrm{J}$, et al. Somatic Activating Mutations in GNAQ and GNA11 Are Associated with Congenital Hemangioma. Am J Hum Genet 2016; 98(4): 789-795.

5. Drolet BA1, Frommelt PC, Chamlin SL, Haggstrom A, Bauman NM, Chiu YE, Chun RH, Garzon MC, Holland $K E$, Liberman L, et al. Initiation and Use of Propranolol for Infantile Hemangioma: Report of a Consensus Conference. Pediatrics 2013; 131(1): 128-140.

6. Hou YZ, Zhao GR, Yuan YJ, Zhu GG, Hiltunen $R$. Inhibition of rat vascular smooth muscle cell proliferation by extract of Ligusticum chuanxiong and Angelica sinensis. J Ethnopharmacol 2005; 99(1): 140-144.

7. Shan $C S, X u Q Q$, Shi $Y H$, Wang $Y$, He ZX, Zheng GQ. Chuanxiong Formulae for Migraine: A Systematic Review and Meta-Analysis of High-Quality Randomized Controlled Trials. Front Pharmacol 2018; 9: 589.

8. Li W, Tang Y, Chen $Y$, Duan JA. Advances in the chemical analysis and biological activities of chuanxiong. Molecules 2012; 17(9): 10614-10651.

9. Zou J, Gao P, Hao X, XU H, Zhan P, Liu X. Recent progress in the structural modification and pharmacological activities of ligustrazine derivatives. Eur J Med Chem 2018; 147: 150-162. 
10. Cai X, Chen Z, Pan X, Xia L, Chen P, Yang Y, Hu H, Zhang J, Li K, Ge J, et al. Inhibition of angiogenesis, fibrosis and thrombosis by tetramethylpyrazine: mechanisms contributing to the SDF-1/CXCR4 axis. PLoS One 2014; 9(2): 88176.

11. Ren Z, Ma J, Zhang P, Luo A, Zhang S, Kong L, Qian C. The effect of ligustrazine on L-type calcium current, calcium transient and contractility in rabbit ventricular myocytes. J Ethnopharmacol 2012; 144(3): 555-561.

12. Lin KH, Kuo WW, Jiang AZ, Pai P, Lin JY, Chen WK, Day $\mathrm{CH}$, Shen $\mathrm{CY}$, Padma VV, Huang CY. Tetramethylpyrazine Ameliorated Hypoxia-Induced Myocardial Cell Apoptosis via HIF-1alpha/JNK/p38 and IGFBP3/BNIP3 Inhibition to Upregulate PI3K/Akt Survival Signaling. Cell Physiol Biochem 2015; 36(1): 334-344.

13. Xu Q, Xia $P$, Li $X$, Wang W, Liu Z, Gao $X$. Tetramethylpyrazine ameliorates high glucose-induced endothelial dysfunction by increasing mitochondrial biogenesis. PLoS One 2014; 9(2): 88243.

14. World Health Organization. Principles of laboratory animal care. WHO Chron 1985; 39: 51-56.

15. Steffy K, Shanthi G, Maroky AS, Selvakumar S. Potential bactericidal activity of $S$. nux-vomica-ZnO nanocomposite against multidrug-resistant bacterial pathogens and wound-healing properties. J Trace Elem Med Biol 2018; 50:229-239.

16. Sayre KR, Dodd RY, Tegtmeier G, Layug L, Alexander SS, Busch MP. False-positive human immunodeficiency virus type 1 western blot tests in noninfected blood donors. Transfusion 2010; 36(1): 45-52.

17. Liu C, Li Z, Huang Z, Zhang K, Hu C, Zuo Z, Li Y. Ligustrazine enhances the hypnotic and analgesic effect of ketamine in mice. Biol Pharm Bull 2018; 41(5): 690696.
18. Martini M, De Santis MC, Braccini L, Gulluni F, Hirsch E. PI3K/AKT signaling pathway and cancer: an updated review. Ann Med 2014; 46(6): 372-383.

19. Li Y, Dai YB, Sun JY, Xiang Y, Yang J, Dai SY, Zhang X. Neuroglobin Attenuates Beta Amyloid-Induced Apoptosis Through Inhibiting Caspases Activity by Activating PI3K/Akt Signaling Pathway. J Mol Neurosci 2016; 58(1): 28-38.

20. Sadri H, Steinhoff-Wagner J, Hammon HM, Bruckmaier RM, Görs S, Sauerwein H. Mammalian target of rapamycin signaling and ubiquitin proteasome-related gene expression in 3 different skeletal muscles of colostrum- versus formula-fed calves. J Dairy Sci 2017; 100(11): 9428-9441.

21. Yuan RR, Kay A, Berg WJ, Lebwohl D. Targeting tumorigenesis: development and use of mTOR inhibitors in cancer therapy. J Hematol Oncol 2009; 2(1): 45.

22. Heinonen H1, Nieminen $A$, Saarela M, Kallioniemi $A$, Klefström J, Hautaniemi S, Monni O. Deciphering downstream gene targets of PI3K/mTOR/p70S6K pathway in breast cancer. BMC Genomics 2008; 9(1): 348.

23. Nasiraei-Moghadam S, Kazeminezhad B, Dargahi L, Ahmadiani A. Maternal Oral Consumption of Morphine Increases Bax/Bcl-2 Ratio and Caspase 3 Activity During Early Neural System Development in Rat Embryos. J Mol Neurosci 2010; 41(1): 156-164.

24. Wu S, Wang B, Chen L, Xiong S, Zhuang F, Huang $X$, Wang $M$, Huang Z. Clinical efficacy of propranolol in the treatment of hemangioma and changes in serum VEGF, bFGF and MMP-9. Exp Ther Med 2015; 10(3):10791083.

25. Li S, Xu G, Gao F, Bi J, Huo R. Expression and association of VEGF-Notch pathways in infantile hemangiomas. Exp Ther Med 2017; 14(4): 3737-3743. 